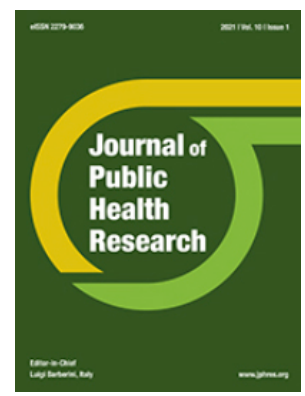

Journal of Public Health Research

elSSN 2279-9036

https://www.jphres.org/

Publisher's Disclaimer. E-publishing ahead of print is increasingly important for the rapid dissemination of science. The Journal of Public Health Research is, therefore, E-publishing PDF files of an early version of manuscripts that undergone a regular peer review and have been accepted for publication, but have not been through the copyediting, typesetting, pagination and proofreading processes, which may lead to differences between this version and the final one.

The final version of the manuscript will then appear on a regular issue of the journal. E-publishing of this PDF file has been approved by the authors.

J Public Health Res 2021 [Online ahead of print]

To cite this Article:

Ghazwani EY, Alayed MSZ, Al-Qahtani AM, et al. The psychological and emotional impact of coronavirus disease on COVID-19 patients in Najran Province, Saudi Arabia: An exploratory study. J Public Health Res doi: 10.4081/jphr.2021.2343

(2) (c) the Author(s), 2021

Licensee PAGEPress, Italy 


\section{The psychological and emotional impact of coronavirus disease on COVID-19 patients in Najran Province, Saudi Arabia: An exploratory study}

Eisa Yazeed Ghazwani ${ }^{1}$, Mohammed Saeed Z Alayed ${ }^{2}$, Awad Mohammed Al-Qahtani ${ }^{1 *}$, Yahya Hussein Ahmed Abdulla ${ }^{3}$, Mohammed Ansar Qureshi ${ }^{4}$, Mugahed Ali Al-Khadher ${ }^{5}$, Sadeq Abdo Alwesabi ${ }^{5}$, Ahmad Abdullah Alshehri', Mosleh Hamad Almas ${ }^{7}$, Sherif Mohamed Khorshid ${ }^{8}$

1 Department of Family and Community Medicine, College of Medicine, Najran University, Najran, Saudi Arabia.

2. Department of Pediatrics, College of Medicine, Najran University, Najran, Saudi Arabia.

3. Department of Community and Mental Health, Faculty of Nursing, Najran University, Najran, Saudi Arabia.

4. Department of Microbiology, College of Medicine, Najran University, Najran, Saudi Arabia.

5. Department of Medical Surgical Nursing, Faculty of Nursing, Najran University, Najran, Saudi Arabia.

6. Department of Clinical Laboratory Sciences, College of Applied Medical Sciences, Najran University, Najran, Saudi Arabia.

7. Public Health Specialist, Assistant Director General of Public Health, Directorate of Health Affairs, Ministry of Health, Najran, Saudi Arabia.

8. Assistant IPC Director KKHN, Medicine and Hygiene Registrar, Directorate of Health Affairs, Ministry of Health, Najran, Saudi Arabia.

Corresponding Author: Dr. Awad Mohammed Alqahtani

Associate Professor, Department of Family and Community Medicine, College of Medicine, Najran University, Najran, Saudi Arabia.

Mobile: 00966530540450 email: awadresearch17@gmail.com

ORCID: https://orcid.org/0000-0002-0873-4776 


\begin{abstract}
Background: The COVID-19 pandemic contributes to a significant mental health crisis. This pandemic caused a widening economic crisis, growing financial loss, and numerous uncertainties. This pandemic brought alarming implications and overall increased risk for psychiatric illness. This study explores the psychological impact experienced by patients who tested positive from coronavirus disease in the Najran region, Saudi Arabia.
\end{abstract}

Design and Methods: This exploratory analysis included 210 COVID-19 positive patients. The study was conducted during a six month period starting from March to September 2020, in two tertiary government hospitals in Najran, Saudi Arabia. Samples were selected using purposive sampling. The researches utilized survey questionnaire and face-to-face interview to collect the data. The statistical data were calculated using IBM Statistical Package for Social Sciences version 2.0 to compute the following statistical formulas: percentage distribution, mean, standard deviation, and Chi-square test of independence.

Results: The findings of this study revealed that the majority of COVID-19 positive patients were middle-aged adults ( $\mathrm{n}=98$ or $46.7 \%$ ), male $(\mathrm{n}=178$ or $84.8 \%$ ), and were non-Saudi nationals ( $\mathrm{n}=132$ or $62.9 \%$ ). It was found out that COVID-19 patients experienced bothersome behaviour at a very high level $(\overline{\mathrm{x}}=2.63 \pm 0.6734)$. Meanwhile, depression $(\overline{\mathrm{x}}=2.51 \pm 0.7070)$, worry $(\overline{\mathrm{x}}=2.23 \pm 0.8811)$, and anxiety $(\overline{\mathrm{x}}=2.21 \pm 0.8719)$ was only at a high level.

Conclusions: The study findings revealed that the majority of participants had high levels of depression, anxiety and bothersome behaviours. However, demographic characteristics like age, sex, and nationality were not significantly related to coronavirus patients' psychological health problems during the pandemic. Assessment and interventions for psychosocial concerns, integration of mental health considerations, consultation with specialists, and treatment for severe psychosocial consequences must be administered in COVID-19 care facilities.

Keywords: Mental health; pandemic; coronavirus infection; psychological stress.

\title{
Introduction
}

In January 2020, the World Health Organization (WHO) declared the COVID-19 outbreak as a public health emergency of international concern. Coronavirus disease (COVID-19) is a highly infectious and contagious disease caused by a newly discovered coronavirus originated from Wuhan, China. ${ }^{1}$ This contagious disease has caused a serious pandemic that made some of the world's leading health systems collapse in a matter of weeks. ${ }^{2}$ The COVID-19 pandemic and resulting economic downturn have negatively affected many peoples' mental health. 
Research shows that more than half of people who lost income and employment over coronavirus have had a negative health impact. ${ }^{3}$ This pandemic caused widening economic crisis, growing financial loss, and numerous uncertainties. ${ }^{4}$ Unemployment rate continues to rise worldwide in the wake of this pandemic and several countries are nearing recession. As the pandemic continues, its more likely that mental health burden will increase because of measures to slow down the spread of virus which include business closure, social distancing, social isolation and financial distress. ${ }^{3}$ The home confinement directives (social isolation, stay at home orders, quarantine) are new concerns for people. ${ }^{5}$ The psychological impact of indefinite home confinement during disease outbreak can lead to negative mental health. ${ }^{6}$ According to the United Nations (2020), COVID-19 contributes to major mental health crisis. Epidemics have been shown to induce general stress across population and associated with mental health problems. ${ }^{3}$ COVID-19 pandemic brought alarming implications and widespread increased risk for psychiatric illness. ${ }^{4}$ American Psychiatric Association (2013) even cited that psychopathology is most likely to develop from natural causes such as life-threatening viral infection. Furthermore, extensive research in disaster mental health has established that psychological and emotional distress is ever present during the COVID-19 pandemic. $^{7}$ Unfortunately, the vast majority of mental health needs still remain unaddressed. ${ }^{8}$

Although lately published data profoundly outlined the physical complaints during the COVID-19 period, a dearth of research targeted psychological well-being. ${ }^{9}$ In this context, dayto-day stressful events, extended home confinement, domestic violence, financial concerns, and internet over-usage are reasons that could affect the mental health of people during this critical period. ${ }^{10}$ In addition, most activities that usually occupy public lives, such as financial, social, schooling and extracurricular activities, have been disrupted. Putting all together, these will have broad-ranging influences on mental health and psychological well-being, depending on their vulnerability and coping abilities in times of crisis. ${ }^{11}$ These interruptions are assumed to worsen or trigger mental disorders, including depression, anxiety, and/or stress-related symptoms.

Our neglect of mental health is becoming obvious nowadays. The crisis response is hampered by our lack of investment in mental health promotion and prevention before the pandemic. ${ }^{8}$ According to the WHO, issues of access to mental health services is now a major concern in population already heavily affected by coronavirus. In this regard, the WHO develop a set of materials that will focus on promoting mental health and psychological support for COVID-19 patients. 
In Saudi Arabia, the first confirmed case of COVID19 was reported on March 7 2020. After announcing the first case in Saudi Arabia, the government response was quick and decisive. A social media campaign was launched, encouraging people to stay at home and abide by the health ministry's instructions. ${ }^{12}$ A lockdown followed this was imposed on Makkah, Madinah, and Riyadh with travel restrictions, and in the next ten days, a 24-Hour curfew was imposed. As of 21 March 2021, Saudi Arabia has reported 385,020 confirmed cases, 374,412 recoveries, and 6,609 deaths. ${ }^{13}$ A recent study conducted by Alkhamees et al., in general population in Saudi Arabia, reported that nearly one-fourth of the sampled general population experienced moderate to severe psychological impact. ${ }^{14}$ The results revealed that health care workers, females, students and those with poor self-reported health status were associated with higher levels of stress, anxiety, and depression symptoms.

The Saudi healthcare authorities perceived the increase of psychological disorders, which prompted them to distribute several guidelines and health messages to the public. Most notably, the Saudi Center for Disease Prevention and Control (CDC) gave a preventive guide for social and mental health centred on prevention and stress and fear management throughout the COVID19 pandemic. ${ }^{15}$ They educated the general population on how to take care of the elderly and the children and gave tips for healthcare workers and managers of health facilities. The Saudi CDC serves the public by working to monitor, measure, evaluate, control, and prevent any risk factors related to the public health in the Kingdom of Saudi Arabia, including communicable and non-communicable diseases, injuries, and other health challenges. The National Centre for Mental Health Promotion promoted a free call counselling centre with mental health specialists available $24 X 7$ to address the public's concerns. ${ }^{16}$ Some hospitals educate the public about mental health, such as King Faisal Specialist Hospital and Research Center had provided social media messages on how to manage stress and anxiety during the pandemic.

There is limited data about psychological impact during the COVID-19 pandemic in Saudi Arabia, especially in the southwestern region of Saudi Arabia. This prompted the researcher to develop the study entitled "The psychological effect of coronavirus disease on patients in Najran Province, Saudi Arabia: An Exploratory Study". This study aimed to explore the psychological impact experienced by patients who tested positive for COVID19. Assessing the current psychological distress in the population of Najran, Saudi Arabia, will help design rapid protection and intervention programs that improve mental health, particularly amongst the psychologically disturbed people. 


\section{Design and Methods}

\section{Study Design}

The exploratory research design study was utilized for this study. As an exploratory research, it aims to explore and clarify the full nature and dimension of the phenomena. As an application to this study, it attempted to better understand the mental health problems commonly experienced by patients diagnosed with coronavirus. Participants provided their promising and significant insightful information into the given situation. Furthermore, this research summarised the key features of the psychological effect of coronavirus disease to the mental health of COVID-19 patients.

\section{Sampling Technique and Sample}

The researchers utilized the purposive sampling technique, purposive sampling means selecting a study participant who is most knowledgeable, most informative, can best contribute, is best representative, and most helpful in giving rightful insight regarding a phenomenon. Inclusion and exclusion criteria were applied in the study. Inclusion criteria that makes the respondents eligible to participate in the study include: a) patient must be positive with coronavirus (COVID-19) disease confirmed by the polymerase chain reaction (RT-PCR) test; b) patient must be from Najran province, Saudi Arabia; c) patients giving consent to participate in this study. The individuals who did not give consent to participate in this study and did not meet the inclusion criteria were excluded from the study.

This paper utilized GPower analysis version 3.2 in computing the total sample size needed for the study. Using the effect size 0.20 , alpha error probability ( $\alpha$ err prob) of 0.05 and power (1$\beta$ err prob) of 0.8 , a total of two hundred and ten (210) patients who tested positive for coronavirus disease were computed and required to partake in the research.

\section{Research setting}

The study was conducted during a six month period starting from March to September 2020, in two tertiary government hospitals in Najran Province, namely: Najran General Hospital and King Khalid Hospital.

\section{Ethical Consideration}

In this study, the following bioethical principles were also observed including justice, autonomy, fidelity, beneficence, non-maleficence. Furthermore, the patient's name was coded with a unique identification number to ensure confidentiality of the patients' pertinent personal 
information. Respondents signed an informed consent and were aware of the risks and benefits of participating from the study. The certificate of ethical research clearance of this research study was obtained from the Technical and Ethical Committee from Najran University with a reference number (IRB: 20-215E). Thus, research ethics was observed and maintained throughout the duration of conducting the study.

\section{Study Tool}

The survey tool is a pre-validated questionnaire designed by subject expert and specialists in psychiatric and mental health. Previous surveys on the psychological impacts of SARS and COVID19 outbreaks were reviewed and the study tool was developed by the research team. The reviewed tools were previously used to access the psychological impact of COVID-19 among the general population in China and Saudi Arabia. ${ }^{14,17,18}$ We made minor changes and included additional questions related to the COVID-19 outbreak.

The researchers provided a survey questionnaire to the participants of the study. COVID-19 patients were asked to complete the survey tool within 15 to 20 minutes. The said survey tool is divided into 2 parts: demographic characteristic and common mental health problems. Instrument validity and reliability: After the development of the instrument, it was tested for face, content, and construct validity by a jury of 5 experts from the fields of psychiatric and mental health. The said tool underwent a pilot study in Najran University Hospital for 20 patients suspected with COVID-19. The tool was tested for reliability and obtained a 0.85 Cronbach alpha reliability score and was considered acceptable and have a good internal consistency.

\section{Data Gathering}

The objectives of this study were (1) to estimate the prevalence of anxiety-depression and distress following exposure to the COVID-19 outbreak in the general population; and (2) to assess the impact of COVID-19 experience on anxiety, depression, and distress symptoms. The research variables were selected based upon previous studies and included: age group, nationality and gender.

The researchers secured a letter of permission to conduct the study from the hospital administration office of selected hospitals. Data collection was conducted at the time of coronavirus pandemic from March to June 2020. The study included a total of 210 COVID-19 positive patients. Data collection was obtained using survey questionnaire and interview. A survey questionnaire was provided to the respondents of the study which was then followed up 
by a face-to-face in-depth interview. Wherein, the research asked the respondents an openended question related to their answers in the survey questionnaire.

\section{Statistical Analysis}

The statistical data were calculated using an IBM Statistical Package for Social Sciences version 2.0 to compute the following statistical formulas: percentage distribution, mean, standard deviation, and Chi-square test of independence.

\section{Results and Discussion}

The demographic characteristics of COVID-19 patients as respondents of the study is depicted in Table 1. Based on the data analysis performed, with a total of 210 COVID-19 patients, it was found out that most of them were middle-aged adults ( $n=98$ or $46.7 \%)$, males $(n=178$ or $84.8 \%$ ), and were non-Saudi nationals ( $\mathrm{n}=132$ or $62.9 \%$ ). The study finding is supported by study of $\mathrm{Li}$, which states that there was a lower prevalence in the female gender and higher prevalence of COVID-19 among males. ${ }^{19}$

Table 2 discusses the most common mental health and psychological problems experienced by patients diagnosed with coronavirus disease at the time of the pandemic. Accordingly, the findings of this study revealed that COVID-19 patients experienced bothersome issues at very high level $(\overline{\mathrm{x}}=2.63 \pm 0.6734)$. Meaning, patients with coronavirus disease were always bothered by problems and situations related to their health. The result of the interview reported that most of the COVID-19 patients described such mental health problem as "they are always being bothered by problems brought by loss of job, financial problems, emotional distress, and fear of dying". Table 3 mental represents the psychological disorders based on the demographic characteristics of the study respondents.

This study revealed that COVID-19 patients experienced a high level of depression $(\overline{\mathrm{x}}=2.51 \pm$ $0.7070)$, worry $(\overline{\mathrm{x}}=2.23 \pm 0.8811)$, and anxiety $(\overline{\mathrm{x}}=2.21 \pm 0.8719)$. Meaning, patients are often depressed, worried and anxious about the problems and situations brought by the coronavirus pandemic. The participants with a high level of depression, revealed in the interview that they started to feel down, unhappy, depressed and hopeless due to this pandemic. Similarly, high level of worry, revealed that COVID-19 patients were always worried and unable to control and stop their worry about the problems brought by the coronavirus disease. These finding are supported by a recent study conducted in Saudi Arabia, who reported moderate to severe anxiety and depression symptoms in around one fifth of the study population. ${ }^{17}$ Coronavirus pandemic causes considerable degree of fear, worry, and concern to the population. ${ }^{4}$ 
Accordingly, it is normal to feel stressed, lonely, and depressed at this type of crisis. Furthermore, research shows that more than half of people who lost income and employment over coronavirus, had a negative health impact like stress and worry. ${ }^{18,20}$ Likewise, anxiety at high level revealed that COVID-19 patients started to feel apprehensive, nervous and anxious about news related to coronavirus. During this unprecedented time of fear and uncertainty, it is more likely that mental health issues will exacerbate. In fact, research shows that there is high prevalence and increased level of depression and anxiety. ${ }^{3,18}$ Nearly half respondents have reported that the negative mental health effect results from worry related to coronavirus. American Psychiatric Association even cited that psychopathology (like depression and anxiety disorders) are more likely to develop during epidemic outbreaks due to natural causes such as life-threatening viral infections. ${ }^{7}$

Meanwhile, the results of this study revealed that COVID-19 patients experienced low selfesteem $(\bar{x}=2.24 \pm 0.97)$, fatigue $(\bar{x}=2.24 \pm 0.97)$, sleeping problems $(\bar{x}=2.24 \pm 0.97)$, suicidal ideation ( $\overline{\mathrm{x}}=2.24 \pm 0.97)$, restlessness $(\overline{\mathrm{x}}=2.24 \pm 0.97)$, feeding problems $(\overline{\mathrm{x}}=2.24 \pm 0.97)$, and poor concentration $(\overline{\mathrm{x}}=2.24 \pm 0.97)$ at considerably moderate level. The result of the interview revealed that patients with coronavirus disease are sometimes experiencing poor esteem, feeling tired, sleeping difficulty, suicidal tendency, restless, poor appetite, overeating, and troubled concentration by problems and situations related to their health. These findings were consistent with the finding of other researches, which showed that low self-esteem is increasingly getting common. ${ }^{3,19}$ During this unprecedented time of fear and uncertainty, it is more likely that negative mental health effects due to social isolation will exacerbate. In addition, the psychological sequelae of quarantine revealed numerous emotional and psychological negative outcomes after the quarantine was lifted like stress, fear, insomnia, anger, irritability, confusion, frustration, boredom, and stigma. ${ }^{5}$

Table 4 depicts the test of a significant relationship between the demographic characteristics and psychological health problems experienced by patients diagnosed with coronavirus disease at the time of pandemic. Chi-square test of independence $\left(\mathrm{r}^{2}\right)$ revealed no statistically significant relationship on the following variables: age and psychological health problems $\left(\mathrm{r}^{2}=10.27, p=0.4142\right)$, sex and psychological health problems $\left(\mathrm{r}^{2}=5.63, p=0.3287\right)$, and nationality and psychological health problems $\left(\mathrm{r}^{2}=8.48, p=0.1972\right)$. Thus, demographic characteristics are not significantly related to the psychological health problems experienced by coronavirus patients at the time of pandemic. A plausible explanation for this observation could be due to the exceptional core family values practiced in Saudi Arabia. Family is a central pillar of Saudi Arabian society. Family forms the basis of most people's social circles, and also 
provides financial and emotional support. ${ }^{21}$ However, since coronavirus is a new disease, limited studies have linked the association between the two variables. ${ }^{18,} 22$ Previous study conducted in China revealed demographic characteristics such as female gender and student status, were significantly associated with a greater psychological impact of the outbreak and higher levels of stress, anxiety, and depression. ${ }^{18}$ Another recent study conducted in USA showed that COVID-19 patients appeared to be at increased risk of psychiatric sequelae, and a psychiatric diagnosis might be an independent risk factor for COVID-19. ${ }^{23}$ Therefore, further studies are warranted to completely assess their relationship. Although the gravity of the pandemic associated psychological illness may diminish over time, as evident from the previous contagious disease outbreaks, a significant consideration is needed from governments and policymakers concerning early detection and treatment of such disorders. These findings could be valuable for educators, counsellors and psychologists in Saudi Arabia and globally as well.

\section{Conclusions}

The present research portrayed the level of anxiety, depression, and distress amongst the general public during the COVID-19 pandemic in Najran, Saudi Arabia. The study findings revealed that majority of participants had high levels of depression, anxiety and bothersome behaviours. However, demographic characteristics like age, sex and nationality were not significantly related to the psychological health problems experienced by coronavirus patients at the time of pandemic.

\section{Strengths and Limitations}

Our study is the first in Najran city, Saudi Arabia, which reported the psychological health of the COVID-19 positive patients and highlights important associated risk factors to provide suggestions for addressing the mental health crisis amid the global pandemic. The study also has some limitations. First, the current study was carried out in a single city, and the sample size selected, cannot represent the whole Saudi population. Second, the study can provide no information about undiagnosed patients with COVID-19. Finally, our results cannot necessarily be generalised to other populations or health-care settings.

\section{Recommendations}

The need to offer suggestions for stress management and effective coping by linking patients to different social and mental health services, patient counselling, open discussion with support 
system, seeking for professional mental health assistance, psychosocial assessment and evaluation, wellness promotion, and psychoeducation. It is imperative that assessment and interventions for psychosocial concerns, integration of mental health considerations, consultation with specialists, and treatment for severe psychosocial consequences should all be administered in COVID-19 care facilities. Communities must work together with mental health teams to develop evidence-based interventions related to disaster mental health and death bereavement care necessary to address psychosocial concerns. Moreover, preventive efforts such as mental health screening, psychoeducation, and psychosocial support are necessary to prevent adverse psychosocial outcomes. Mental health advised also include staying connected, physically active, sleeping well and staying calm.

Data availability: Data are available from Dr. Awad Mohammed Al-Qahtani (contact details: mobile: 00966530540450; email: awadresearch17@gmail.com) for researchers who meet the criteria for access to confidential data.

Conflict of Interest: None declared

Funding: Supported by King Fahd Medical City, Riyadh, Saudi Arabia. 


\section{References}

1. Al-Raddadi RM, Shabouni OI, Alraddadi ZM, et al. Burden of Middle East Respiratory Syndrome Coronavirus infection in Saudi Arabia. J Infect Public Health 2020;13:692-6.

2. Williams OD. COVID-19 and private health: Market and governance failure. Development (Rome) 2020;63:181-90.

3. Kaiser Family Foundation [Internet]. The implications of COVID-19 for mental health and substance use. Accessed: Mar 21, 2021. Available from: https://www.kff.org/coronaviruscovid-19/issue-brief/the-implications-of-covid-19-for-mental-health-and-substance-use/

4. Pfefferbaum B, North CS. Mental health and the Covid-19 pandemic. N Engl J Med 2020;383:510-2.

5. Brooks SK, Webster RK, Smith LE, et al. The psychological impact of quarantine and how to reduce it: Rapid review of the evidence. Lancet 2020;395:912-20.

6. DiGiovanni C, Conley J, Chiu D, Zaborski J. Factors influencing compliance with quarantine in Toronto during the 2003 SARS outbreak. Biosecur Bioterror 2004;2:26572.

7. Friedman M. Trauma- and stressor-related disorders. In: Diagnostic and Statistical Manual of Mental Disorders-5. American Psychiatric Association, 2013.

8. United Nations. COVID-19 and the need for action on mental health. 2020.Available from: https://unsdg.un.org/sites/default/files/2020-05/UN-Policy-Brief-COVID-19-and-mentalhealth.pdf

9. Torales J, O'Higgins M, Castaldelli-Maia JM, Ventriglio A. The outbreak of COVID-19 coronavirus and its impact on global mental health. Int J Soc Psychiatry 2020;66:317-20.

10. Guessoum SB, Lachal J, Radjack R, et al. Adolescent psychiatric disorders during the COVID-19 pandemic and lockdown. Psychiatry Res 2020;291:113264.

11. Golberstein E, Wen H, Miller BF. Coronavirus Disease 2019 (COVID-19) and mental health for children and adolescents. JAMA Pediatr 2020;174:819-20.

12. Ministry of Health [Internet]. MOH reports first case of Coronavirus infection. 2020. Accessed: Mar 21, 2021. Available from: https://www.moh.gov.sa/en/Ministry/MediaCenter/News/Pages/News-2020-03-02$\underline{002 . \operatorname{aspx}}$

13. Worldometer [Internet]. Coronavirus update (live): 123,579,348 cases and 2,724,015 deaths from COVID-19 virus pandemic. Accessed: Mar 21, 2021. Available from: https://www.worldometers.info/coronavirus/?fbclid=IwAR3cCqZbJ6WON_zD33oONzf vKRDzFxfQpuexSSog6BRC5aZ48W4t8cXAego

14. Alkhamees AA, Alrashed SA, Alzunaydi AA, et al. The psychological impact of COVID19 pandemic on the general population of Saudi Arabia. Compr Psychiatry 2020;102:152192.

15. Saudi Center for Disease Prevention and Control. Novel corona virus (2019-nCoV) infection guidelines V1.2. 2021. Accessed: Mar 21, 2021. Available from: https://covid19.cdc.gov.sa/wp-content/uploads/2020/03/Coronavirus-Disease-2019Guidelines-v1.2.pdf.pdf 
16. King Faisal Specialist Hospital and Research Centre (KFSHRC). Managing stress \& anxiety. 2021. Accessed: Mar 21, 2021. Available from: https://www.kfshrc.edu.sa/en/home/covid/managingstress

17. Joseph R, Lucca JM, Alshayban D, Alshehry YA. The immediate psychological response of the general population in Saudi Arabia during COVID-19 pandemic: A cross-sectional study. J Infect Public Health 2021;14:276-83.

18. Wang $\mathrm{C}$, Pan $\mathrm{R}, \mathrm{W}$ an $\mathrm{X}$, et al. Immediate psychological responses and associated factors during the initial stage of the 2019 coronavirus disease (COVID-19) epidemic among the general population in China. Int J Environ Res Public Health 2020;17:1729.

19. Lin HC, Chen CC. Disease prevention behavior during the COVID-19 pandemic and the role of self-esteem: An extended parallel process model. Psychol Res Behav Manag 2021;14:123-35.

20. Elhessewi GMS, Almoayad F, Mahboub S, et al. Psychological distress and its risk factors during COVID-19 pandemic in Saudi Arabia: A cross-sectional study. Middle East Curr Psychiatr 2021;28:7.

21. Cultural Atlas [Internet]. Saudi Arabian culture - core concepts. Accessed: June 25, 2021. Available from: https://culturalatlas.sbs.com.au/saudi-arabian-culture/saudi-arabianculture-core-concepts

22. Alamrawy RG, Fadl N, Khaled A. Psychiatric morbidity and dietary habits during COVID-19 pandemic: A cross-sectional study among Egyptian youth (14-24 years). Middle East Curr Psychiatr 2021;28:6.

23. Taquet M, Luciano S, Geddes JR, Harrison PJ. Bidirectional associations between COVID-19 and psychiatric disorder: retrospective cohort studies of 62354 COVID-19 cases in the USA. Lancet Psychiatry 2021;8:130-40. Erratum in: Lancet Psychiatry 2021;8:e1. 
Table 1. Demographic Characteristics of Coronavirus (COVID-19) Patients as Respondents of the Study

\begin{tabular}{lll}
\hline Demographic Characteristics & $\begin{array}{l}\text { Frequency } \\
(\mathbf{n})\end{array}$ & $\begin{array}{l}\text { Percentage } \\
(\%)\end{array}$ \\
\hline Age & & \\
\hline 13-20 years old (Adolescents) & 9 & 4.2 \\
21-35 years old (Young adults) & 77 & 36.7 \\
36-55 years old (Middle-aged adults) & 98 & 46.7 \\
56 years old and above (Older adults) & 26 & 12.4 \\
\hline Gender & & \\
\hline Male & 178 & 84.8 \\
Female & 32 & 15.2 \\
\hline Nationality & & \\
\hline Saudi & 78 & 37.1 \\
$\quad$ Non-Saudi & 132 & 62.9 \\
\hline TOTAL & $\mathbf{N = 2 1 0}$ & $\mathbf{1 0 0 . 0 \%}$ \\
\hline
\end{tabular}

Table 2. Psychological Health Problems Experienced by COVID-19 Patients

\begin{tabular}{llll}
\hline Mental Health Problems & $\begin{array}{l}\text { Frequency } \\
\text { (n) }\end{array}$ & $\begin{array}{l}\text { Percentage } \\
(\mathbf{\%})\end{array}$ & $\begin{array}{l}\text { Verbal } \\
\text { Interpretation }\end{array}$ \\
\hline Bothersome & 2.63 & 0.6734 & Very High \\
Depression & 2.51 & 0.7070 & High \\
Worry & 2.23 & 0.8811 & High \\
Anxiety & 2.21 & 0.8719 & High \\
Low self-esteem & 2.04 & 0.9324 & Moderate \\
Fatigue & 2.04 & 0.9245 & Moderate \\
Sleeping problems & 2.03 & 0.9120 & Moderate \\
Suicidal ideation & 1.94 & 0.9337 & Moderate \\
Restless & 1.93 & 0.9410 & Moderate \\
Feeding problems & 1.93 & 0.9461 & Moderate \\
Poor concentration & 1.89 & 0.9293 & Moderate
\end{tabular}

Legend: 1.00-1.40 Very low level; 1.41-1.80 Low level; 1.81-2.20 Moderate level; 2.21-2.60 High level; and 2.61-3.00 Very high level 
Table 3. Psychological Health Problems based on Demographic characteristic experienced by COVID-19 Patients $(\mathrm{n}=210)$

\begin{tabular}{|c|c|c|c|c|c|c|c|c|c|c|}
\hline $\begin{array}{l}\text { Demographic } \\
\text { Characteristics }\end{array}$ & $\begin{array}{l}\text { Frequency } \\
\text { (n) }\end{array}$ & $\begin{array}{l}\text { Percentage } \\
(\%)\end{array}$ & \multicolumn{2}{|c|}{ Depression } & \multicolumn{2}{|c|}{ Anxiety } & \multicolumn{2}{|c|}{$\begin{array}{l}\text { Low self- } \\
\text { esteem }\end{array}$} & \multicolumn{2}{|c|}{$\begin{array}{l}\text { Worrisome } \\
\text { behaviour }\end{array}$} \\
\hline \multicolumn{3}{|c|}{ Age } & n & $\%$ & $\mathbf{n}$ & $\%$ & $\mathbf{n}$ & $\%$ & n & $\%$ \\
\hline $\begin{array}{l}\text { 13-20 years old } \\
\text { (Adolescents) }\end{array}$ & 9 & 4.2 & 9 & 100 & 8 & 88.88 & 7 & 77.77 & 8 & 88.88 \\
\hline $\begin{array}{l}\text { 21-35 years old } \\
\text { (Young adults) }\end{array}$ & 77 & 36.7 & 68 & 88.31 & 38 & 49.35 & 44 & 57.14 & 43 & 55.84 \\
\hline $\begin{array}{l}\text { 36-55 years old } \\
\text { (Middle-aged } \\
\text { adults) }\end{array}$ & 98 & 46.7 & 88 & 89.79 & 73 & 74.48 & 60 & 61.22 & 71 & 72.44 \\
\hline $\begin{array}{l}56 \text { years old } \\
\text { and above } \\
\text { (Older adults) }\end{array}$ & 26 & 12.4 & 23 & 88.46 & 25 & 96.15 & 21 & 80.76 & 25 & 96.15 \\
\hline \multicolumn{3}{|c|}{ Gender } & $\mathbf{n}$ & $\%$ & $\mathbf{n}$ & $\%$ & $\mathbf{n}$ & $\%$ & $\mathbf{n}$ & $\%$ \\
\hline Male & 178 & 84.8 & 159 & 89.32 & 122 & 68.53 & 105 & 58.98 & 127 & 71.34 \\
\hline Female & 32 & 15.2 & 29 & 90.62 & 29 & 90.62 & 22 & 68.75 & 26 & 81.25 \\
\hline \multicolumn{3}{|c|}{ Nationality } & $\mathbf{n}$ & $\%$ & $\mathbf{n}$ & $\%$ & $\mathbf{n}$ & $\%$ & $\mathbf{n}$ & $\%$ \\
\hline Saudi & 78 & 37.1 & 68 & 87.17 & 54 & 69.23 & 48 & 61.53 & 55 & 70.51 \\
\hline Non-Saudi & 132 & 62.9 & 114 & 86.36 & 85 & 64.39 & 72 & 54.54 & 84 & 63.63 \\
\hline
\end{tabular}

Table 4. Test of Significant Relationship between the Impact of Demographic Characteristics in the Psychological Health Problems of Patients with Coronavirus.

\begin{tabular}{lllll}
\hline $\begin{array}{l}\text { Variable } \\
\mathbf{( x )}\end{array}$ & $\begin{array}{l}\text { Variable } \\
\mathbf{( y )}\end{array}$ & $\begin{array}{l}\text { Chi-square value } \\
\left(\mathbf{r}^{\mathbf{2}} \mathbf{n}\right.\end{array}$ & $\boldsymbol{p}$-value & Interpretation \\
\hline Age & Psychological & 10.27 & 0.4142 & Not Significant* \\
Sex & Health Problems & 5.63 & 0.3287 & Not Significant* \\
Nationality & 8.48 & 0.1972 & Not Significant \\
\hline${ }^{*} p$-value is significant if $p<05$ & & &
\end{tabular}

